\title{
Course Quality Starts with Knowing Its C-Index
}

\author{
Neville I. Williams \\ School of Computer Science Engineering and Mathematics, \\ Flinders University, Adelaide, South Australia, Australia
}

\author{
Neville.Williams@flinders.edu.au
}

\begin{abstract}
Every university strives to provide high quality educational programs and ultimately to produce excellent graduates from those programs. In order to be confident that the programs are of an appropriate level, a substantial amount of effort is given to conducting quality assurance exercises that include an examination of course programs and assessments, student performances, industry consultation, and benchmarking against other similar institutions and courses. The processes involved are qualitative and judgmental in nature since there is currently no agreed metric that can contribute effectively to improving the assessment of quality in degree courses.

This paper examines the use of an approach that is based on the analysis of learning outcome statements proposed for the subjects comprising degree programs. The analysis and subsequent calculations enable course profiles for those degrees to be determined. The resultant profiles allow quantitative comparisons to be made on the degree courses prior to any review of course output artifacts. The approach described uses the SOLO Taxonomy as an integral part of the determination of a value that is used as an indicator of the educational rigour or cognitive demands expected in the degree course. This is labelled the C-Index.

The innovative concept of converting what were previously only qualitative assessments into quantitative metrics in this manner enables the expansion of our understanding of course quality approaches. The benefits of applying this approach are that it assists with the production of course profiles, facilitates the comparisons of courses, and therefore enhances benchmarking processes by potentially providing baseline data for course accreditations.
\end{abstract}

Keywords: course metric, course evaluation, course quality, course profile, benchmarking, C-Index.

\section{Introduction}

The higher education sector is a competitive sector in which universities compete with one another on the basis of reputation, tradition, and perception of excellence in both the teaching and research fields.

Material published as part of this publication, either on-line or in print, is copyrighted by the Informing Science Institute. Permission to make digital or paper copy of part or all of these works for personal or classroom use is granted without fee provided that the copies are not made or distributed for profit or commercial advantage AND that copies 1) bear this notice in full and 2) give the full citation on the first page. It is permissible to abstract these works so long as credit is given. To copy in all other cases or to republish or to post on a server or to redistribute to lists requires specific permission and payment of a fee. Contact Publisher@InformingScience.org to request redistribution permission.
Enormous efforts are put into the marketing of the "University brand" and the range and quality of the courses offered. The concept of course quality is an essential component within the Australian university sector, and many attempts are made to demonstrate the achievement of high quality levels and satisfaction through teaching assessments, student output assessments, course accreditation 
panels, benchmarking teams, graduate surveys and similar. All of these instruments are output focused, and important in their own right. As post-process activities their role in attempting to validate institutional quality standards has been asserted over many years as an integral part of the quality assurance and quality management processes. However, a question that needs to be asked is whether there exists a suitable input-side instrument, or pre-activity tool, that can be used to profile a course in a meaningful way. By assessing a course before it is delivered, the variables that affect the course outputs such as the teaching team involved, operational factors, and the particular mix of students in the cohort, all of which may change from one year to the next, are eliminated. It is the purpose of this paper to demonstrate that an effective input-side profiling tool is feasible and to explore its value in attempting to answer the question of "How does this course compare with other courses?"

The methods described in this paper demonstrate how a new metric, labelled the C-Index, may be calculated. Potential applications of the C-Index are proposed, highlighting its utility as a useful metric at both the institutional level and across institutions as a supplement to current benchmarking processes.

\section{Background}

Our world is filled with a number of metrics that are used to provide initial expectations to relevant people to assist in their decision-making or to enable evaluators to set a baseline expectation for further judgments. In the University research sector there exists the h-index, an index that attempts to measure both the productivity and impact of the published work of a researcher (Hirsch, 2005); Tofallis (2012) discussed the issue of attempting to modify the approach to determining university rankings in the UK, and noted that "the "league tables' ... are here to stay"; in some Olympic events such as diving, dance, and gymnastics there are associated degree of difficulty factors that judging panels use to base their scores of competitor performances; and there are numerous other examples where such metrics are applied. Presently there is no similar metric to indicate the difficulty or learning expectations of degree courses in Australian universities. The only real metric available to gauge courses is the cut-off score that high school students need to attain to receive an offer of enrolment into the course. However this is based on student quota management rather than course content.

The concept of quality has taken on different interpretations depending on the context and domain area in which it appears. It has perhaps gained its greatest common usage in matters relating to manufacturing and production industries and is often attributed to the work of Walter Shewhart in introducing scientific method in improving the work process during the 1920s (Zairi, 2013). His work using statistical process control, and the subsequent efforts of Deming, Juran and Crosby have led to the application of quality principles to management processes and the term "Total Quality Management" has arisen to become a paradigm followed by many enterprises (Zairi, 2013).

There is no particular reason why universities cannot adopt some or many of the quality management principles in the education process. It is often suggested that there are five underlying quality management principles that need to be embraced (Kuei \& Lu, 2013), which are:

- Facilitating increased awareness of quality and market signals;

- Enabling conditions for quality;

- Adopting a systems approach;

- Achieving greater communication and alignment between cross-organisational units; and

- Examining for congruence with quality objectives. 
One of the key elements that becomes clear when one delves further into the quality management paradigm is the philosophy of continuous improvement and building quality into the product. When applied to an educational program, the opportunities begin at the course design and specification stage. Accordingly, one of the objectives of this paper is to examine the specifications for the subjects in a degree program in terms of the learning outcomes in order to gauge the level of learning rigour that the course proposes.

Within the context of this paper it is important to specify the meanings of some of the educational terminologies used as they vary enormously between institutions. The term "course" for example may mean a semester of study on a particular topic in one place (eg the Introductory Mathematics course), or a full degree program in another (such as the Bachelor of Arts course). In this paper the terms used are:

\begin{tabular}{|l|l|l|}
\hline \multicolumn{3}{|c|}{ Table 1: Terminology Interpretations } \\
\hline Term & \multicolumn{1}{|c|}{ Meaning } & Alternative Terminology \\
\hline Course & A complete degree program & Degree, award \\
\hline $\begin{array}{l}\text { Course } \\
\text { Rule }\end{array}$ & $\begin{array}{l}\text { Specification for the combination of subjects to be com- } \\
\text { pleted in order to satisfactorily complete the course }\end{array}$ & $\begin{array}{l}\text { Degree Regulations, Sched- } \\
\text { ule of Study }\end{array}$ \\
\hline Subject & $\begin{array}{l}\text { A prescribed study program in a specific discipline area, } \\
\text { typically over one semester or term }\end{array}$ & Topic, Course \\
\hline $\begin{array}{l}\text { Unit } \\
\text { Value }\end{array}$ & $\begin{array}{l}\text { The effective weight of the subject in the student load, } \\
\text { typically expressed as a fraction of a full-time year }\end{array}$ & $\begin{array}{l}\text { Course credits, Credit } \\
\text { Points, Units }\end{array}$ \\
\hline $\begin{array}{l}\text { Learning } \\
\text { Objective }\end{array}$ & $\begin{array}{l}\text { A student learning objective written in behavioural } \\
\text { terms }\end{array}$ & Learning Outcome \\
\hline
\end{tabular}

Typically, a Course is comprised of a number of Subjects in a combination specified by the Course Rule. Each Subject is assigned a Unit Value, and will normally have one or more Learning Objectives often expressed in behavioural terms and therefore usually prefaced with a statement such as "On successful completion of this subject the student will be able to ...". Accordingly, the set of learning objectives may be thought of as the subject specification for that particular subject.

In practice, each course invariably has its own course aims and objectives, which are intended to be addressed by one or more of the individual subject learning objectives. These overarching aims and objectives are intended to convey a sense of the overall graduate attributes that should be realised in the successful students, and provide some thematic relevance or intent across the subjects in the course.

When examining the learning objectives of subjects it is necessary to build upon the previous work undertaken in this area, and in particular to draw upon the development of taxonomies for learning objectives. Early studies of student learning objectives gave rise to the emergence of qualitative approaches to assist in their creation and/or examination. Two significant taxonomies relevant to this area, which will be discussed briefly, are the revised Bloom Taxonomy, and the SOLO (Structure of Observed Learning Outcome) Taxonomy.

The revised Bloom Taxonomy (Anderson \& Krathwohl, 2001) is an evolved form of the original Taxonomy of educational objectives proposed by Bloom in the 1950s (Bloom, Engelhart, Furst, 
Hill, \& Krathwohl, 1956), which essentially created a framework for classifying the statements of what was expected for students to learn through the teaching process. The revised Taxonomy has expanded the Knowledge dimension of the original Taxonomy and is now represented as a twodimensional matrix mapping the Knowledge dimension against the Cognitive dimension (Krathwohl, 2002). The tabular form allowed the analysis of the objectives of a subject, and in particular, enabled an indication of the extent to which more complex types of knowledge and cognitive processes were involved.

Several studies have investigated the suitability of the Bloom Taxonomy in the field of Computer Science (Gluga, Kay, Lister, Kleitman, \& Lever, 2012; He \& Brandt, 2007; Oliver, Dobele, Greber, \& Roberts, 2004; Scott, 2003; Whalley et al., 2006), and most appear to examine the various micro-level aspects of individual subject components such as the practical tests, assignment work, and examinations. The analysis undertaken by Oliver et al. (2004) described the determination of a 'Bloom Rating' using a scale of 1 to 6 corresponding to the cognitive levels of the Bloom Taxonomy for parts of the assessment instruments in several subjects that were considered, and concluded that there were observable differences in the two different subject streams reviewed. It was highlighted in Sitthiworachart and Joy (2004) that the Bloom levels 1 to 3 were considered as surface learning, and the levels 4 to 6 were viewed as deep learning.

Another significant educational taxonomy is the SOLO Taxonomy proposed by Biggs and Collis (1982), which states the key attribute as "provides a measure of the quality of assimilation in terms of structural complexity" and leads to the ability to "assess student work in terms of its quality ..." (J. Biggs, 2011). It is this intention of quality assessment that has contributed to the SOLO Taxonomy becoming a popular tool in matters dealing with the quality of educational programs. The SOLO Taxonomy embraces a slightly simpler classification mechanism than the revised Bloom Taxonomy, having just five levels in its structure, those being identified and explained by several authors (J. Biggs, 1979, 2011; J. B. Biggs \& Collis, 1982; J. B. Biggs \& Tang, 2007) as:

1. Pre-Structural - sometimes regarded as an uninformed view;

2. Uni-Structural - where some basic ideas are used but often only able to comprehend a limited part of the area;

3. Multi-Structural - where several ideas are able to be considered but a focussed and possibly incomplete solution may be proposed;

4. Relational - where most of the relevant data is used in forming a conclusion; and

5. Extended Abstract - where the context is often viewed as only a single instance of the more general case.

By reviewing objectives in terms of the functionality expected at different levels it is possible to assess learning outcomes or behavioural objectives using the SOLO Taxonomy. Examination of stated learning objectives reveals that there are typical verbs that may be associated with each of the levels in the taxonomy, and this enables the classification of those objectives accordingly. It was pointed out by Biggs and Collis (1982) that the SOLO Taxonomy is hierarchical and student learning tends to be progressive from the more quantitative outcomes associated with Levels 2 and 3, through to becoming more qualitative at the higher Levels 4 and 5. Terms describing these aspects are surface learning at the quantitative stage, and deep learning at the qualitative stage. Killen (2005) distinguishes between deep knowledge and deep understanding, explaining that deep knowledge is considered as a characteristic of the content that students are studying, and that deep understanding is something that develops in the mind of the learner as they learn about deep knowledge. Killen further suggests that attaining deep understanding would correspond to being classified at the highest levels on both the SOLO Taxonomy and the revised Bloom Taxonomy, thus making it equivalent to the deep learning expressed in both taxonomies. 
By combining the taxonomic analysis of degree courses with a scoring method that enables a metric to be calculated for each subject in a degree, and then applying the course rules for the degree, a course profile for the degree can be established. A new metric labelled the C-Index is a measurement value for the degree that is intended to be used as an indicator of the learning rigour expected in that course.

This paper will show the method used to calculate the C-Index and further demonstrate how the associated course profile may be used as a comparative tool to assist in course mapping, alignment, benchmarking and other quality improvement initiatives.

\section{Calculation Approach}

The use of educational taxonomies has been demonstrated over many years as being an effective way of classifying various elements of the teaching process, from individual learning tasks to complete learning programs. In almost all cases the conventional approach has been to use the qualitative descriptors of the relevant taxonomy to classify and analyse the item under consideration. In the more numerate disciplines of science and technology, the use of qualitative descriptors is less appealing than having values arising from quantitative methods to interpret.

One of the more significant attempts to quantify the qualitative data of taxonomic analysis was undertaken in a major study in Denmark where some 550 subject syllabi in the science faculties of two universities were used to determine similarities or differences between the different domain areas (Brabrand \& Dahl, 2007). In this study the SOLO Taxonomy was used as the theoretical base for the work, and the approach used was to score the learning objectives listed for each subject against the SOLO Level most closely aligned to the objective statement.

Under the SOLO Taxonomy philosophy there are 5 Levels by which learning objectives can be classified and the technique used in the Brabrand and Dahl study has simply mapped the learning objective assessment to the corresponding level number in the taxonomy. Hence the potential values between 1 and 5 would be allocated to each of the learning objectives, although in reality this became a range of 2 to 5 since no formalised learning objective would be targeted at the prestructural or ab-initio state. One of the important features of the SOLO Taxonomy is that the Level structure is cumulative in nature (J. Biggs, 1979) so that an item being classified at Level 4, by implication, also incorporates all the competencies of Levels 2 and 3. The integral nature of choosing the level number as the competency mapping value also creates two distinct presumptions, or derived assumptions. In the language of mathematics, scores which have the same value imply equality. Therefore any objective that is classified as being at Level 3 is presumed to be equivalent to every other objective that is classified as being at Level 3, and similarly for each of the other levels. While there may be slight individual differences between the learning outcomes within a particular SOLO Level, the equivalence assumption is an important aspect of the process of quantifying learning objectives.

The second assumption follows from the scoring of learning objectives according to the SOLO Level against which they are classified. The integral progression from 2 to 3 to 4 to 5 has an equal difference of 1 between each number. Translating this to the learning outcomes assessments means that there is an implied equal distance assumption when evaluating the learning outcomes in this manner. That is, the jump between learning task competencies from Level 2 to Level 3 is the same as the jump from Level 3 to Level 4 and from Level 4 to Level 5.

A further subdivision of that scale was made by identifying that Levels 2 and 3 in the SOLO Taxonomy were more quantitatively oriented with key classification verbs such as "identify", "list", "apply method" being highlighted as the more mechanical aspects of the learning tasks. At the same time, Levels 4 and 5 were identified as being more qualitatively oriented by virtue of requiring higher order learning skills such as "analyse", "compare", "explain causes", "predict" and 
"reflect". A more comprehensive list of the table of verbs and their SOLO Taxonomy classification is covered in the publications of Brabrand and Dahl (2007), and Williams (2013).

For each of the levels in the SOLO Taxonomy, a list of verbs that were typical of learning objectives for that level was prepared. Then, when examining a stated learning objective, it was straight-forward to map the objective to a particular level number. In practice, the numeric mapping was not so simple because many learning objectives were stated in compound form where there could be multiple verbs and therefore potentially multiple classifications for a learning objective. An example statement such as "define the term .... and list the key components to be found in it" has two distinct parts, namely the "define" part, which is classified as SOLO Level 2, and "list" which is classified as SOLO Level 3. The solution proposed by Brabrand and Dahl was to average the scores for the learning objective across the compound parts. In this example the resultant score would be 2.5 which is the average of the values 2 and 3 . A similar problem occurs when looking at different subject syllabi, as some will have just a few statements of learning objectives and others will have many. Accordingly Brabrand and Dahl chose to average the scores of each of the subject learning objectives so that each subject returned a single value in the scoring range. They labelled this method as the "double-weight averaging scheme".

To demonstrate the application of this approach, the following example is used. For one of the second-year programming subjects in a computer science degree program, the behavioural objective statements are given as:

At the completion of the subject, students are expected to be able to:

1. Understand and appropriately use the language and terminology of data abstraction and object-oriented programming

2. Describe common data structures and choose appropriate data structures for specific application needs

3. Write code to build and manipulate common linked data structures

4. Understand and appropriately use the language and terminology of algorithm analysis

5. Determine the time and space complexity of simple algorithms

6. Describe the advantages and disadvantages of different algorithmic approaches in specific application contexts

7. Implement common searching and sorting algorithms

8. Read $C++$ programs and use $C++$ to solve simple data abstraction problems

It can be seen that virtually all of these objective statements are either specifically compound statements (e.g., understand AND appropriately use...) or implied compound statements (e.g. implement ... and ...). The term 'understand' does not conveniently map to the SOLO Taxonomy. With appropriate analysis of what is stated, and in consultation with the subject coordinator to interpret the intention of what is stated, the SOLO scores for the subject were found to be:

1. "Understand and appropriately use" in the context of the language and terminology elements were most appropriately classified as SOLO-3 $=>3.0$;

2. "Describe ... and choose ..." were similarly best classified as SOLO-3 => 3.0;

3. "Write code ..." required the application of method, but also the application of theory, resulting in both SOLO-3 and SOLO-4 => 3.5;

4. "Understand and appropriately use ..." in the context of algorithm analysis goes beyond straight-forward classification and requires analysis and explanation of causes, hence SOLO $-4=>4.0$;

5. "Determine ..." was considered to be more of application of theory than merely performing an algorithm $=>4.0$; 
6. "Describe advantages and disadvantages ..." in this case was considered to be both the compare and contrast application of theory as well as the ability to theorize and predict, giving scores at both SOLO-4 and SOLO-5 $=>4.5$;

7. "Implement ..." while clearly incorporating the apply algorithmic method component of SOLO-3 was considered to also require the integrate aspect of SOLO-4 $=>3.5$;

8. "Read ... and use ..." involved both SOLO-2 elements of follow instructions and also the application of theory at SOLO-4 $=>(2+4) / 2=3.0$.

The mean score for these eight learning objectives (the SOLO score for the subject) is then calculated, giving a resultant value of 3.56. [The other specifically identifiable subjects in the degree were similarly evaluated and a resultant SOLO score for each subject was obtained.]

This fundamental method of quantifying the learning objectives for a subject can be extended across whole domain areas, as was the case in the Brabrand and Dahl study, or restricted to a more specific subset if a narrower focus is required. When used in conjunction with the rules for a particular degree program, it becomes possible to determine a unique value for that degree. Such an approach was first demonstrated by Williams (2013) to highlight the application of the technique to a Bachelor of Information Technology degree, which was labelled as a Course-Index score, or simply a C-Index. Williams also demonstrated that the technique was equally applicable to evaluations undertaken using the Bloom Taxonomy, but for consistency with the Brabrand and Dahl approach the SOLO Taxonomy was chosen as the preferred base. (Williams, 2013)

More formally, the double-weight averaging scheme when used in conjunction with the course rules for a degree program enable a distinct year-level score to be determined. This can be expressed mathematically as:

$y=$ year-level score $=\sum_{i=1}^{n} w_{t} S_{t}$, for the subjects in that year-level where

$\mathrm{S}_{\mathrm{i}}=\quad$ SOLO score for a specific subject in a course

$\mathrm{w}_{\mathrm{i}}=\quad$ the weight of the subject expressed as the proportional contribution to a full-time year of study in the student workload

$\mathrm{n}=\quad$ number of subjects included in the full-time year of study (for the given year level)

In the particular case where each subject has the same weight in the study program, that is, all contribute equally to a year of study, then the year-level score can be restated as:

$\mathrm{y}=$ year-level score $={ }^{n} \sum_{i=1}^{n} s_{i}$, for the subjects in that year-level

Under the assumptions in Williams (2013), the compulsory or core subjects are included separately, the selective subjects, where students choose a required number of subjects from a limited list of alternatives, are evaluated individually but averaged to give a representative value for the selective subjects, and the general elective subjects are scored as being equivalent to the average value of the core subjects under the presumption that the educational rigour across year levels within a given institution should be approximately similar even though they may come from different domain areas. 
It then follows that the C-Index is expressed as:

$$
\mathrm{C}=\frac{1}{m} \sum_{\mathrm{i}=1}^{m} y_{Z}
$$

where

$$
\begin{aligned}
& y_{j}=\text { year-level score for a course } \\
& m=\text { number of years of study for the degree program }
\end{aligned}
$$

There are of course other definitions of C-Index, one being the in the realm of association theory (Garcia 2008), and another being a software tool for indexing books, journals and other textual material (Indexing-Research 2012). However, despite there being other areas where the term C-Index is used, this being a quite different domain area, the author sees no real terminology conflict or resultant confusion.

The methodology in this research built on the Williams approach, using the same double-weight averaging scheme applied to several different courses from the same university to investigate the level of difference or similarity between those courses. The analysis undertaken covered a related discipline degree program of the same duration and also a similarly related degree program of a different duration. In total, three distinct degrees were analysed - two three-year degrees and a four-year degree.

\section{Results}

The method to determine the C-Index for a course has been shown in the previous section as being a combination of applying the Brabrand and Dahl double-weight averaging scheme and the Williams approach to analysing the subjects comprising a degree in conjunction with the course rules for degree. Careful interpretation of the classification of the subjects as core, selective, or elective within the course rules influences the manner in which the subject SOLO score is used in the overall C-Index calculation.

In this analysis, a three-year Bachelor of Information Technology degree (BInfoTech) required 20 distinct subjects to be evaluated, a three-year Bachelor of Computer Science degree (BCompSc) required 28 distinct subjects to be evaluated, and a four-year Bachelor of Engineering (Software Engineering) degree (BEng(SW)) required 44 distinct subjects to be evaluated. The resultant scores were grouped by year level and weighted according to the proportion of the full-time equivalent year of study allocated to the subject. The results obtained are shown in the accompanying Table 2.

\begin{tabular}{|l|r|r|r|}
\hline \multicolumn{4}{|c|}{ Table 2: Course SOLO Scores } \\
\hline $\begin{array}{l}\text { Course } \\
\text { Year Level }\end{array}$ & $\begin{array}{r}\text { BInfoTech } \\
\text { Weighted } \\
\text { SOLO Scores }\end{array}$ & $\begin{array}{r}\text { BCompSc } \\
\text { Weighted } \\
\text { SOLO Scores }\end{array}$ & $\begin{array}{r}\text { BEng(SW) } \\
\text { Weighted } \\
\text { SOLO Scores }\end{array}$ \\
\hline First Year & 3.43 & 3.45 & 3.55 \\
\hline Second Year & 3.56 & 3.63 & 3.68 \\
\hline Third Year & 3.86 & 3.77 & 3.87 \\
\hline Fourth Year & - & - & 4.00 \\
\hline Degree Total & 10.85 & 10.85 & 15.10 \\
\hline C-Index & $\mathbf{3 . 6 2}$ & $\mathbf{3 . 6 2}$ & $\mathbf{3 . 7 8}$ \\
\hline
\end{tabular}




\section{Discussion}

The initial observations from the results data is that there was an increasing progression of the weighted SOLO scores through each year level of study in each of the degrees analysed, which is both expected and reassuring. It is expected in that one would hope that the learning required in each year level of a degree course did become more involved and more demanding. It is reassuring that the courses examined did display this characteristic.

A second observation is that the two three-year degrees, the BInfoTech and BCompSc, returned the same overall C-Index value although their individual year-level scores were slightly different. A partial explanation for this result is that those two degrees share a modest number of common subjects in their study programs.

The difference in C-Index for the BEng(SW) course highlights the impact of a four-year degree compared with a three-year degree, where there is the expectation that the later year subjects will contain more advanced work requiring higher levels of academic rigour, and the results data support this assertion.

A question that arises is whether the raw data provides sufficient information as it stands. To investigate this, other statistical measures were explored including the standard deviation to consider the spread of the data, and a year-weighted mean. These additional statistics are shown in Table 3.

\begin{tabular}{|l|r|r|r|}
\hline \multicolumn{4}{|c|}{ Table 3: Expanded SOLO Scores } \\
Year Level & $\begin{array}{r}\text { BInfoTech } \\
\text { Weighted } \\
\text { SOLO Scores }\end{array}$ & $\begin{array}{r}\text { BCompSc } \\
\text { Weighted } \\
\text { SOLO Scores }\end{array}$ & $\begin{array}{r}\text { BEng(SW) } \\
\text { Weighted } \\
\text { SOLO Scores }\end{array}$ \\
\hline First Year & 3.43 & 3.45 & 3.55 \\
\hline Second Year & 3.56 & 3.63 & 3.68 \\
\hline Third Year & 3.86 & 3.77 & 3.87 \\
\hline Fourth Year & - & - & 4.00 \\
\hline Degree Total & 10.85 & 10.85 & 15.10 \\
\hline C-Index & $\mathbf{3 . 6 2}$ & $\mathbf{3 . 6 2}$ & $\mathbf{3 . 7 8}$ \\
\hline Standard Deviation & .221 & .160 & .199 \\
\hline Year-Weighted Mean & 3.69 & 3.67 & 3.85 \\
\hline
\end{tabular}

With so few data points the standard deviation is unlikely to reveal any particularly significant information for an individual course at the overall course level. Its application is more likely to be appropriate in a comparative manner across similar or related courses, or perhaps discipline areas. However, even then there would need to be a dramatic difference noted before particular concerns were raised. As can be seen in this data set, the BInfoTech displays the greatest amount of spread and the BCompSc displays the least amount of spread based on the year-level scores. A graph of the distribution of the SOLO Scores for each of the subjects in the BInfoTech degree is shown in Figure 1. 


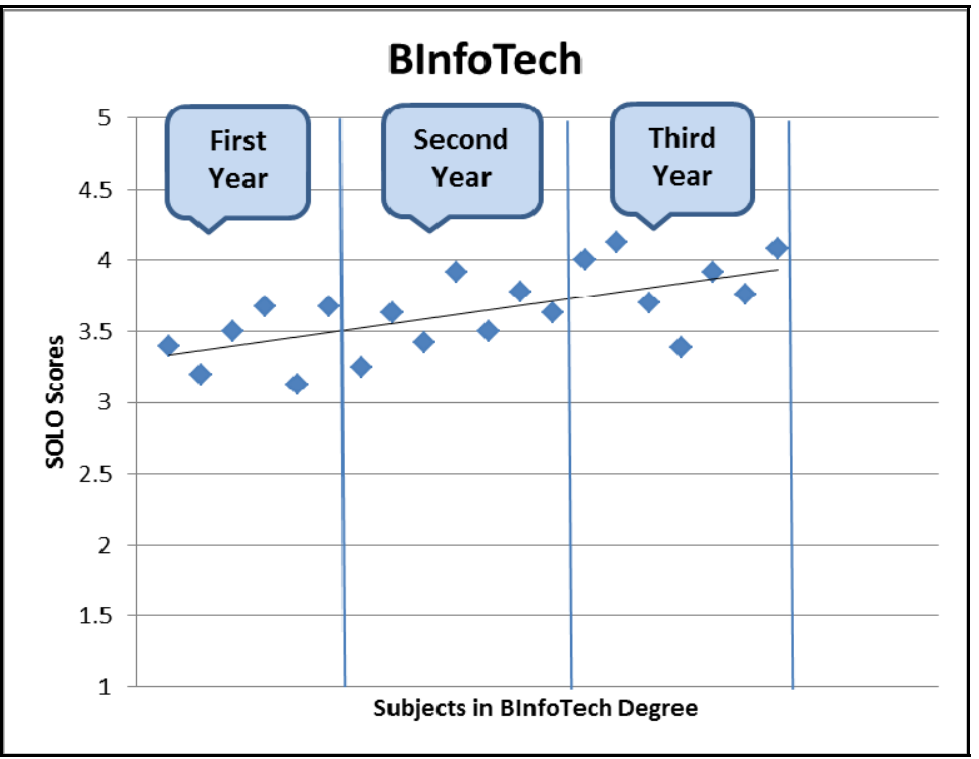

Figure 1: Distribution of BInfoTech SOLO Scores
The rationale behind calculating a year-weighted mean is that in a number of areas the later year subjects are perceived to be more important than early year subjects and should therefore be given more weight in the overall calculation. While this does bias the outcome towards the assessments given to the later year subject scores, it is debatable as to whether it provides a better view of the course or whether it is simply an unnecessary complicating factor. It could be validly argued that the material content of later year studies does require higher order cogni-

tive skills at SOLO 4 and SOLO 5 levels, but this has only become possible because of the formative learning that has occurred in the earlier years of study and the development of learning maturity in the student. As a result the educational rigour may be viewed as being comparable across the year levels of the course as it is more closely matched to what a student can be hoped to achieve at that stage in their educational development. This could be considered as their expected learning potential. Hence the year-weighted mean is more likely to be an unnecessary complication on the calculation than being able to provide a more meaningful C-Index value.

The method used to determine the subject year-level scores and the course C-Index involves a number of repetitions of using averaging techniques. There is some validity in the argument that repeated averaging may throw into question the merit of the statistic obtained as the overall granularity of the data set may become coarser. One of the stronger criticisms of the mean as a measure of central tendency is that it is unduly affected by extreme observations (Moore \& McCabe, 2003; Selvanathan, Selvanathan, Keller, \& Warrack, 2007), but in this case there is no opportunity for extreme values to occur as the scoring range is between 2 and 5 . However it is proposed that the resultant value is a guidance number that should be used in conjunction with other factors rather than being taken as a stand-alone value on which to base interpretations and judgments.

A more meaningful application of the techniques discussed would be in the analytical work when reviewing courses to use the statistics obtained to highlight potential outlier subjects within courses. For example, using the mean and standard deviation values, under Chebyshev's Theorem (Selvanathan et al., 2007), at least $75 \%$ of observations should lie within two standard deviations of the mean, and at least $90 \%$ of observations should lie within three standard deviations of the mean.

Applying the relevant calculations to the data already examined a set of control limits can be obtained for each of the three degrees, and then the individual subjects which form the degree can be classified and grouped relative to the C-Index as shown in Table 4. 


\begin{tabular}{|l|c|c|c|}
\hline \multicolumn{1}{|c|}{ Table 4: SOLO Score Distributions by Course } \\
\hline \multicolumn{1}{|c|}{ Subject SOLO-score range } & $\begin{array}{c}\text { \# of subjects } \\
\text { BInfoTech }\end{array}$ & $\begin{array}{c}\text { \# of subjects } \\
\text { BCompSc }\end{array}$ & $\begin{array}{c}\text { \# of subjects } \\
\text { BEng(SW) }\end{array}$ \\
\hline More than 3 std dev below mean & 0 & 1 & 0 \\
\hline Between 2 and 3 std dev below mean & 1 & 3 & 0 \\
\hline Within 2 std dev of mean & 17 & 19 & 41 \\
\hline Between 2 and 3 std dev above mean & 2 & 2 & 2 \\
\hline More than 3 std dev above mean & 0 & 3 & 1 \\
\hline
\end{tabular}

Initial observations suggest that the degrees BInfoTech and BEng(SW) appear to be consistent in terms of their statements of learning objectives, but the BCompSc seems to have too many subjects that fall outside the acceptable limits, and may therefore become subjects of interest. Hence, using the data in the examples in this paper, a course review of the BCompSc might choose to look back over the individual subjects and consider the learning requirement specifications of subjects where the subject SOLO score was outside the range of either two or three standard deviations from the mean - ie. 3.30 to 3.94 (3.62 $\pm 2 \times 0.160)$ [two standard deviations either side of the mean], or 3.14 to 4.10 for three standard deviations from the mean.

Under this proposed analysis method for the BCompSc degree, there are potentially 4 subjects $(14 \%)$ that could come under some scrutiny as they fall outside the three standard deviation range, or 9 subjects (32\%) that are outside the two standard deviation range. For those which are below the range boundaries the question that arises is whether the stated or expected learning demands should be raised to be more consistent with other subjects in the degree or is it that the statement of learning objectives is inadequately expressed and therefore does not match the level of learning rigour that will be demanded of the students. For those above the range boundaries the converse applies, resulting in the question of whether too much is being asked of the students in that degree program at that stage of their learning, or equally the expression of learning expectation is higher than that being delivered. Depending on the outcomes to those review questions, it may be that if the statements of learning objectives are deemed to be appropriate then other questions could be framed in terms of the learning support being provided to the students to enable them to better cope with the higher levels of learning expectation. It is also important to identify the year level of the subjects that are flagged as being of interest. In the above example it was noted that all the five subjects above the upper boundaries were final year subjects, and of those below the range boundaries the lowest scoring subject was a first-year introductory subject and the other three subjects in the 2 to 3 standard deviation range included one first-year subject, one second-year subject and one third-year subject.

A different view could be held when looking at the data from a different perspective. For example, the chart in Figure 1 shows a clear upwards trend, so the simple control limits based on the overall course C-Index may not necessarily reveal what was hoped. It may be better to perform the analysis based on the year-level means, which would give a stepped set of control limits upon which to frame the evaluations. This may be the most appropriate approach given that the method of calculating the $\mathrm{C}$-Index is based on averaging year-level scores.

It is beyond the scope of this paper to answer those questions, for that is the task of the course architects and curriculum designers of those subjects. What is shown however, is that this approach may be used as a tool to highlight or flag particular subjects as being worthy of further scrutiny for the reasons mentioned. 


\section{Conclusion}

The analysis undertaken in this research has achieved several distinct outcomes. Firstly it confirms the methodology of the European based Brabrand and Dahl study as being equally applicable in the Australian context. By extension, this should therefore be equally applicable to any educational system that has a clearly defined set of course rules and subjects with appropriately described learning objectives.

Secondly the quantification of subject learning objectives, when applied against the specific course rules, has enabled the creation of a metric which has been labelled the C-Index for a degree course. The C-Index can be used as an indicator of proposed learning rigour for the course, and this value may enable both students and educators to compare courses and assist in the selection of the most appropriate course for the student.

Thirdly, the comparative analysis undertaken highlights that the course profiles may be used as effective tools to supplement contemporary benchmarking processes, ultimately leading to improved quality in tertiary course offerings.

While the research documented in this paper has been confined to the courses offered by one university in a particular domain area, the future value of the techniques should become more evident when examining a broader set of course data across a number of universities both in the Australasian region and internationally. From the viewpoint of individual university administrations, the techniques are applicable to benchmark curricula across the domains of various faculties, particularly to highlight areas of inconsistency. From the viewpoint of industry groups or national focus areas, the techniques are relevant in providing benchmarking criteria for exercises such as course accreditation and other quality determination tasks.

\section{References}

Anderson, L. W., \& Krathwohl, D. R. (Eds.). (2001). A taxonomy for learning, teaching and assessing: A revision of Bloom's taxonomy of educational objectives. New York: Addison Wesley Longman.

Biggs, J. (1979). Individual differences in study processes and the quality of learning outcomes. Higher Education, 8(4), 381-394.

Biggs, J. (2011). SOLO taxonomy. Retrieved 8 May 2013, from http://www.johnbiggs.com.au/academic/solo-taxonomy/

Biggs, J. B., \& Collis, K. F. (1982). Evaluating the quality of learning: The SOLO Taxonomy. New York: Academic Press.

Biggs, J. B., \& Tang, C. (2007). Teaching for quality learning at university (3rd ed.). Maidenhead, UK: Open University Press.

Bloom, B. S., Engelhart, M. D., Furst, E. J., Hill, W. H., \& Krathwohl, D. R. (1956). Taxonomy of educational objectives: Handbook I: Cognitive domain. New York: David McKay.

Brabrand, C., \& Dahl, B. (2007). Constructive alignment and the SOLO taxonomy: A comparative study of university competences in computer science vs mathematics. Paper presented at the Seventh Baltic Sea Conference on Computing Education Research (Koli Calling 2007), Koli National Park, Finland.

Gluga, R., Kay, J., Lister, R., Kleitman, S., \& Lever, T. (2012). Coming to terms with Bloom: An online tutorial for teachers of programming fundamentals. Paper presented at the The Fourteenth Australasian Computing Education Conference (ACE 2012), Melbourne.

He, L., \& Brandt, P. (2007). WEAS: A web-based educational assessment system. Paper presented at the The 45th Annual Southeast Regional Conference (ACM-SE45), New York.

Hirsch, J. E. (2005). An index to quantify and individual's scientific research output. Proceedings of the National Academy of Sciences, 102(46), 16569-16572. 
Killen, R. (2005). Programming and assessment for quality teaching and learning. Southbank: Thomson.

Krathwohl, D. R. (2002). A revision of Bloom's taxonomy: An overview. Theory into Practice, 41(4), 212218.

Kuei, C.-h., \& Lu, M. H. (2013). Integrating quality management principles into sustainability management. Total Quality Management \& Business Excellence, 24(1-2), 62-78. doi: $10.1080 / 14783363.2012 .669536$

Moore, D. S., \& McCabe, G. P. (2003). Introduction to the practice of statistics (4th ed.). New York: W. H. Freeman and Company.

Oliver, D., Dobele, T., Greber, M., \& Roberts, T. (2004). This course has a Bloom rating of 3.9. Paper presented at the The Sixth Australasian Computing Education Conference, Dunedin.

Scott, T. (2003). Bloom's taxonomy applied to testing in computer science classes. Journal of Computing Sciences in Colleges, 19(October), 267-274.

Selvanathan, A., Selvanathan, S., Keller, G., \& Warrack, B. (2007). Australian business statistics (4th ed.). South Melbourne: Thomson.

Sitthiworachart, J., \& Joy, M. (2004). Using web-based peer assessment in fostering deep learning in computer programming. Paper presented at the International Conference on Education and Information Systems (EISTA 2004), Orlando, FL.

Tofallis, C. (2012). A different approach to university rankings. Higher Education, 63(1), 1-18.

Whalley, J. L., Lister, R., Thompson, E., Clear, T., Robbins, P., Kumar, P. K. A., \& Prasad, C. (2006). An Australian study of reading and comprehension skills in novice programmers, using the Bloom and SOLO taxonomies. Paper presented at the Eighth Australasian Computing Education Conference, Hobart, Tasmania.

Williams, N. I. (2013). Constructing a course profile by measuring course objectives. International Journal of Digital Information and Wireless Communications, 3(4), 16-28.

Zairi, M. (2013). The TQM Legacy - Gurus' contributions and theoretical impact. The TQM Journal, 25(6), 659-676.

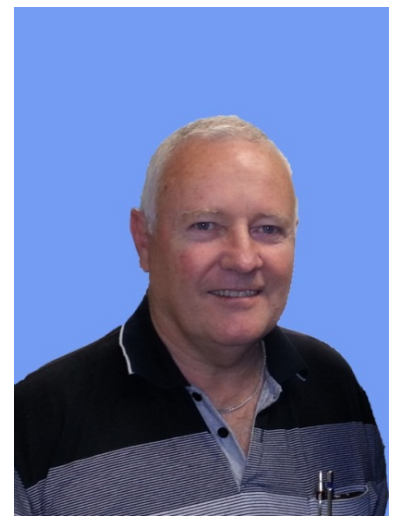

\section{Biography}

Neville Williams has had a long association with various levels of the education sector, having taught in secondary schools, the TAFE sector, the university sector, and managed the training function nationally for a chartered accounting firm. Interspersed with these educational roles he has worked as a computer programmer and for a number of years ran his own business as a computing consultant, specialising in advisory services to Small and Medium Enterprises and Government in South Australia.

Mr. Williams' major areas of research interest span the topics of teaching and learning in ICT, strategic management using ICT systems, and enterprise information security. 